\title{
Agricultural Demand Response Aggregators in Electricity Markets: Structure, Challenges and Practical Solutions- a Tutorial for Energy Experts
}

\author{
Hessam Golmohamadi ${ }^{1}$ (B) \\ Received: 28 November 2019 / Accepted: 25 August 2020 / Published online: 3 September 2020 \\ (C) Springer Nature Singapore Pte Ltd. 2020
}

\begin{abstract}
Worldwide, the demand-side flexibility is subject to extensive researches to hedge against the increasing penetration of intermittent renewable power and/or reduce the peak demand of the power system. The electricity consumptions, including residential, agricultural and industrial, have responsive behavior which can provide demand flexibility to the power system when aggregated and coordinated properly. Against the literature on residential and industrial sectors, the Demand Response (DR) potentials of the agricultural sector are still a challenge for energy policy-makers. This paper aims to fill the gap conducting a research study into DR opportunities for agricultural electricity consumption. This paper first introduces the main barriers to the agricultural DR, e.g. the size of the irrigation system, flexibility of water delivery, onsite labor, and on-farm power electronic control devices. Secondly, practical solutions are proposed to eliminate barriers. Finally, in order to facilitate the integration of demand flexibilities to the power system, a novel structure is suggested for the first time as Agricultural Demand Response Aggregator (ADRA). Therefore, reviewing the main barriers of ADR programs, suggesting practical solutions to break the barriers and finally suggesting a workable structure for the ADRA are the main contributions. To sum up, this tutorial gives energy experts a general overview to implement DR programs on agricultural lands optimizing the power system operation.
\end{abstract}

Keywords Agricultural $\cdot$ Demand response aggregator $\cdot$ Electricity market $\cdot$ Flexibility $\cdot$ Irrigation system

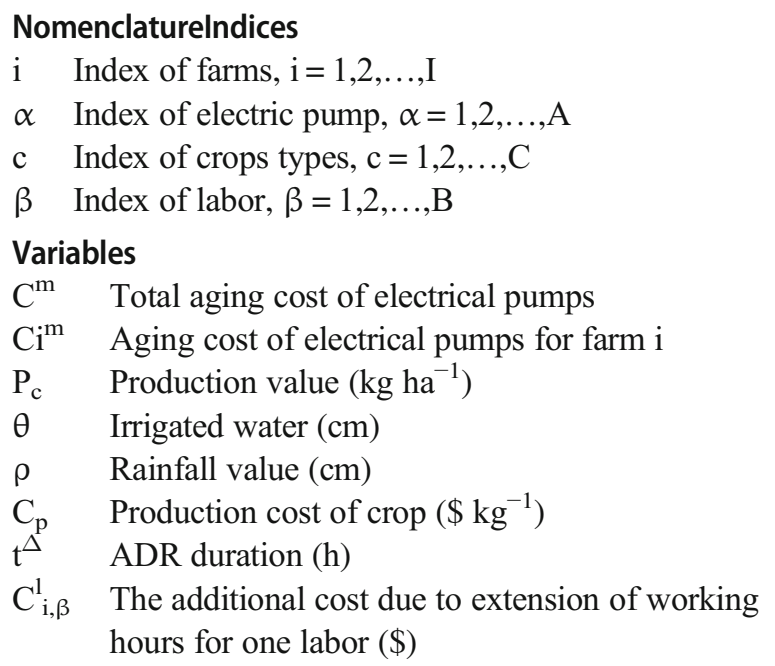

Hessam Golmohamadi hessamgolmoh@cs.aau.dk

1 Department of Computer Sciences, Aalborg University, 9220 Aalborg, Denmark
$\mathrm{C}^{1} \quad$ Total cost due to extension of working hours (\$)

$\pi_{1} \quad$ Probability of failure due to deterioration

$\pi_{0} \quad$ Probability of random failure

$\mathrm{C}^{\mathrm{FI}} \quad$ Financial incentive for the ADRPs (\$)

$\mathrm{C}_{\mathrm{e}} \quad$ Cost of electricity consumption for crop $\left(\$ \mathrm{~kg}^{-1}\right)$

$\eta_{\kappa} \quad$ Risk to benefit ratio

$\lambda^{\mathrm{BM}} \quad$ Electricity price at balancing market (\$/MWh)

$\lambda^{\mathrm{DA}} \quad$ Electricity price at day-ahead market (\$/MWh)

\section{Constants}

$\gamma_{i, \alpha} \quad$ Maintenance cost for pump i in farm $\alpha$

$v_{i, \alpha} \quad$ Number of start-up/shut down for pump $i$

$\mathrm{K}_{\text {labor }}$ Hourly wage for labor $(\$ / \mathrm{h})$

Acronyms

ADRA Agricultural demand response aggregator

ADRP Agricultural demand response program

IPG Iran Power Grid

GWP Groundwater pump

SWP Surface water pump

WBP Water booster pump

ADSM Agricultural Demand Side Management

AEEM Agricultural Energy Efficiency Measures 


$\begin{array}{ll}\text { APLS } & \text { Agricultural Permanent Load Shifting } \\ \text { VSD } & \text { Variable Speed Drives } \\ \text { TOU } & \text { Time of Use } \\ \text { CPP } & \text { Critical Peak Pricing } \\ \text { EDP } & \text { Extreme Day Pricing } \\ \text { GFI } & \text { Gravity Fed Irrigation } \\ \text { SI } & \text { Sprinkler Irrigation (SI) } \\ \text { SDI } & \text { Subsurface Drip Irrigation } \\ \text { LFI } & \text { Low-Flow Irrigation } \\ \text { ACSP } & \text { Agricultural Communication Service Provider } \\ \text { FCU } & \text { Farm Central Unit } \\ \text { RBR } & \text { Risk to Benefit Ratio }\end{array}$

\section{Introduction}

\section{Problem Identification and Motivation}

During the last decade, the share of renewable power, i.e. wind and solar power, has been increasing in the power systems all over the world $[1,2]$. For example, in the Danish sector of Nordic Electricity Market, the share of renewable power is scheduled to be increased from $5.5 \mathrm{GW}$ ( $44 \%$ of total installed capacity) at 2015 to $6.4(55 \%)$ and $8.1 \mathrm{GW}(60 \%)$ at 2020 and 2025, respectively [3]. In this way, the renewable distributed generations are taking the place of retired gas-fired engines. Increasing the share of renewable power, the intermittency and volatility of the supply-side in the power system increases considerably [4]. On the other hand, the profile of electricity demand is changing fundamentally. In the transportation system, the traditional fossil-fuel vehicles, including public transportation and private cars, are gradually replaced with the electric ones [5] [6]. Moreover, the world rate of electricity consumption ( $\mathrm{kWh}$ per capita) is increasing due to increasing social welfare [7]. Increasing intermittency in the supply-side and increasing the rate of electricity consumption in the demand side, new kinds of power flexibility are needed to preserve the power systems. Therefore, demand-side flexibility is essential to ensure the power system flexibility or it may put the future power system at risk.

To overcome the problem, there are some kinds of power flexibilities in the electrical demands, i.e. residential, commercial, agricultural and industrial levels, which can be extracted and integrated. The key factor of demand-side flexibility is that power flexibility must be integrated. In contrast, segregated power flexibilities cannot affect the power system effectively.

In order to aggregate the demand-side flexibilities, two necessary measures should be taken. First of all, the demand flexibilities of each class of consumers should be aggregated by a specialized demand response aggregator (DRA). Therefore, residential, commercial, agricultural and industrial demand response aggregators (RDRA, CDRA, ADRA,
IDRA) should be organized. Secondly, a practical coordination approach should be provided to integrate the DR opportunities of the DRAs, i.e. RDRA, CDRA, ADRA, IDRA.

To achieve the aim, three levels of research studies need to be carried out as follows:

Level 1. an investigation of demand flexibilities among different electricity consumptions, i.e. residential, commercial, agricultural and industrial sectors.

Level 2. proposing a mathematical structure for the DRAs, i.e. RDRA, CDRA, ADRA, IDRA.

Level 3. developing a coordination technique to integrate the flexibility potentials of different kinds of DRAs.

\section{Literature Review}

Increasing the penetration of renewable power, the power system needs new forms of demand flexibilities to hedge against the intermittency and volatility $[8,9]$. In the literature, prominent research studies were conducted in the areas of residential [10], commercial [11] and industrial [12, 13] sectors. Regarding the agricultural sector, although some research studies were carried out but barely any studies can be seen to integrate the agricultural demand-side flexibility to power systems. In this way, previous research studies have concentrated on energy efficiency programs in farms. First of all, in 2013, the US Department of Energy provided a general overview of demand response opportunities in California agricultural lands [14]. Later, in 2015, the study had been extended to propose framework of automated demand response in the farms [15]. In 2016, a neuro-fuzzy Smith predictor controller is proposed to increase the efficiency of water irrigation system [16]. In 2017, a scoping study reviewed and analyzed the water, energy, and food nexus in 7 regions including Asia, Europe, Oceania, North America, South America, Middle East and Africa [17]. In 2019, a dynamic mathematical model design of photovoltaic water pumps was presented as a guide tool to electrical energy potential assessment for irrigation system [18]. Moreover, four nature inspired algorithms were used to optimize the design model of photovoltaic pumping of irrigation systems [19]. At the same time, Cuckoo search algorithm and fuzzy logic controller was suggested to optimize the irrigation station process of farms [20].

While the previous studies concentrated on water-energy nexus, new research studies come up with an idea of integration of agricultural-side flexibilities to the power systems. First of all, paper [21] provides a comprehensive review to depict the roadmap of agriculture-clean energy system and analyze their feasibilities and advantages. Afterward, in order to provide a great deal of flexibility to the power system, a restructuring in agricultural industry is suggested [22]. Paper [23] used data-driven approach and a robust optimization 
programming to manage the energy consumption of an agricultural waste-to-energy network under uncertainty. It is worth mentioning that the robust optimization is a practical solution to energy management in energy systems under uncertainty [24]. In [25] an integrated water-food-energy nexus modelling and optimization approach is proposed to manage the real-time irrigation systems in agricultural lands. Solar water pump is a practical solution which is proposed to provide agricultural demand-side flexibility to the power system [26].

Regarding the previous studies, what are missing in the literature are as follows:

1). Investigation of demand flexibilities for the agricultural sector.

2). Suggesting a practical model for the ADRA.

3). Devising a coordination technique to integrate the agricultural flexibilities into the residential and industrial ones.

In order to fill the gap, this paper conducts a comprehensive study in Levels 1 and 2 in the area of agricultural electricity demands. To achieve the aim, first of all, this study investigates different concepts of demand-side flexibilities among agricultural electricity consumptions. In this way, a detailed study is carried out to identify the DR opportunities, barriers and challenges (Level 1). Secondly, a basic structure is suggested for the first time, for the ADRAs (Level 2). Devising a coordination technique between ADRAs and the other DRAs is suggested for future researches (Level 3). It is no doubt that the coordination method shall be included but not due to the scope and length limit.

\section{Basic Idea and Features}

In the literature, to the best of our knowledge, no comprehensive study is done to integrate the flexibility potentials of agricultural sector into the electricity market. Against the background, this paper aims to narrow the gap by proposing ADRAs applicable in the electricity market. The basic idea behind this study can be illustrated by the schematic diagram in Fig. 1. This figure reveals that agricultural electricity consumptions can be divided into three main categories as follows:

1) Electrical demands which can be scheduled $24 \mathrm{~h}$ prior to energy delivery time.

2) Electrical demands which can be adjusted 60 to $10 \mathrm{~min}$ prior to energy delivery time.

3) Electrical demands which can be balanced in near real-time.
Fig. 1 Conceptual diagram of agricultural DR classification

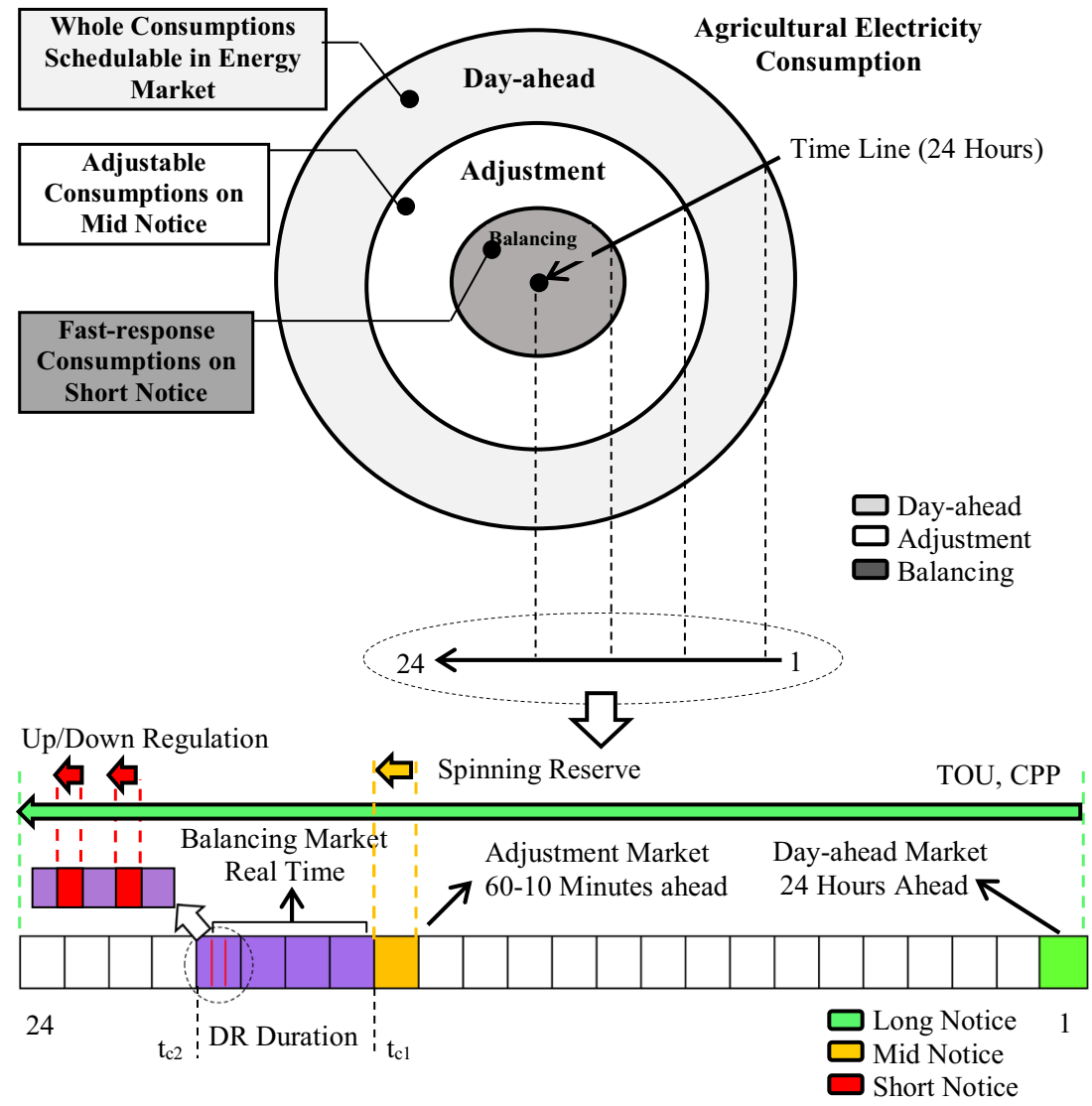


The first category of demands can be scheduled in the dayahead market which is cleared $24 \mathrm{~h}$ prior to energy delivery. The second category can be adjusted in the adjustment market 60 to $10 \mathrm{~min}$ prior to energy delivery. Finally, the fastresponse demands can respond to the DR events in near real-time condition of balancing markets.

Therefore, the main aim of this research study is to investigate the DR opportunities of agricultural electricity consumptions and propose a three-stage time-oriented DR program compatible with the three trading floors of the electricity markets, i.e. day-ahead, adjustment and balancing markets.

To achieve the aim, all the agricultural electrical demands subject to the DR events are investigated. In this way, opportunities, barriers, and the main constraints are described. Afterward, the agricultural electrical demands categorize into three main classes based on their response time to the DR events, i.e. long, mid and short notice DR events. Finally, a practical model for the ADRA is proposed to make the agricultural DRPs applicable in the modern structure of electricity markets.

\section{Paper Organization and Contributions}

This paper concentrates on the agricultural DRPs to fill the gaps in the literature. To sum up, the main contributions of the study are as follows:

1). Investigation of flexibilities potentials and the main barriers in agricultural electricity consumptions.

2). Categorization of agricultural demands into three main classes based on their response time to the DR events.

3). Suggestion of a practical model for ADRAs to facilitate the integration of farms flexibilities to the electricity market.

The remainder of the paper is organized as follows: in section 2, the fundamental of agricultural demand response program is defined. In section 3 , the electricity consumptions of farms are presented and classified. Section 4 describes the different types of agricultural demand-side management. In section 5, the main barriers to the ADRPs are illustrated. Section 6 suggests practical solutions to break the barriers. In section 7 the basic structure of ADRAs is proposed. Finally, Section 8 concludes the proposed approach.

\section{Description of Agricultural Demand Response}

Agricultural Demand response programs (ADRPs) are a set of measures taken by the agricultural electricity consumers (growers) to reduce or shift the electrical demands in response to (i) requests sent from an ADRA or (ii) dynamic electricity price of the electricity market when power shortage/excess occurs or system reliability is jeopardized. Generally, there are two kinds of DRPs for the agricultural sector as follows:
1). Incentive-based ADRPs: in these programs, a financial incentive is allocated to the farmers to motivate them to participate in the ADRPs.

2). Price-based ADRPs: in the price-based programs no financial supports are considered for the farmers. Instead, the financial burden of electricity usage is shifted towards the farmers' shoulder.

The farmers' motivation to participate in the ADRPs is as follows:

1). Reducing the charge of electricity bills in the price-based ADRPs.

2). Providing an income in the incentive-based ADRPs.

Broadly, the ADRPs inherently depend on the nature of supply-side regarding the fact that the power system is mainly supplied by the renewable (intermittent) generation units or thermal (deterministic) ones. It is evident that the ADRPs should be scheduled differently for these two kinds of power systems.

\section{Deterministic-Supplied Power Systems}

In the power systems with high penetration of thermal generation units, the ADRPs aim to reduce the peak demand. In such power systems, the peak demands occur in certain time hours which can be determined months before.

As a large-scale deterministic-supplied power system, the Iran Power Grid (IPG) has been experiencing high peak hours during hot summer days, especially at midday hours. The major reason for the increased peak demand is the cooling systems of residential and commercial consumers [12]. Developing ADRPs, the striking features of the supplied power system should be extracted. This issue is necessary to schedule ADRPs fitted with the power system perfectly.

Figure 2 describes the key features of the IPG in terms of annual peak demand and duration. Based on Fig. 2(a), the IPG has two peak demands daily as follows:

1) Day-peak demand between hours 12 to 16

2) Night-peak demand between hours 20-22

In addition, subfigure 2(b) reveals that the annual peak demand of IPG occurs in the hottest days of summer, i.e. between 5 July and 5 August.

The main feature of this kind of power systems is that the peak demand occurs in certain time hours which can be determined on very long notice; therefore, the ADRPs should be scheduled to reduce the peak demands with determined DR duration. In this way, agricultural electricity consumptions highly increase at the midday hours coincident with the peak of the power system. As a result, the ADRPs are under slight uncertainty due to the known peak hours of the power system. 


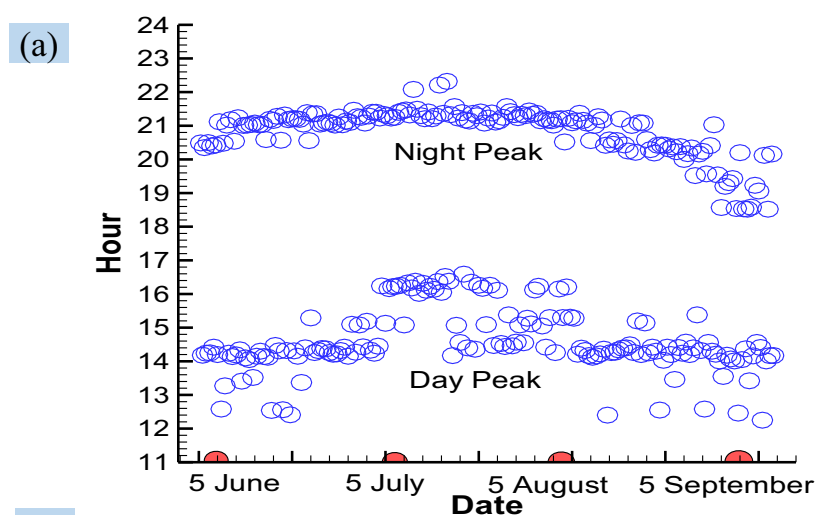

(b)

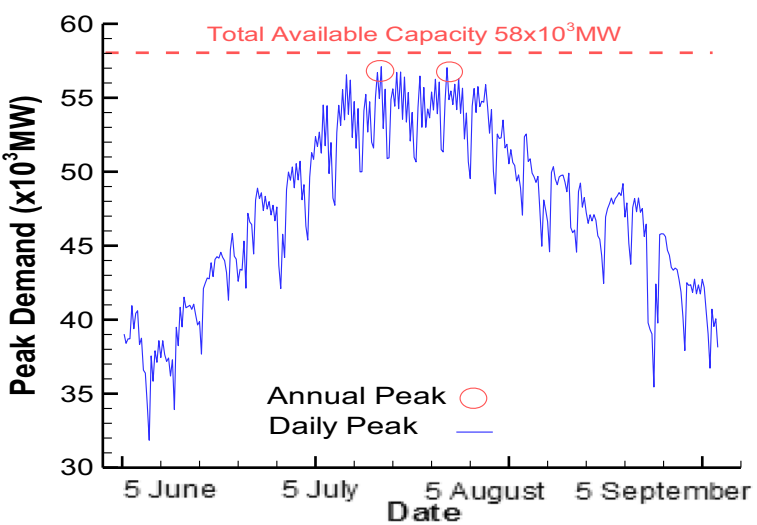

Fig. 2 Key features of IPG (a) Daily peak time (b) Daily peak demand. The raw data is extracted from Iran Grid Management Company (IGMC) [27] which is publicly available. The data corresponds to date from 5 June to 5 September 2018

In this study, in order to avoid tedious explanations, this kind of power systems is denoted by Type A.

In the Iran economy, electricity has been heavily subsidized by the government for decades. Due to the early recession, and, thus, budget limit, the electricity price is under financial liberalization. This will result in higher cost of crops production if no DRPs are implemented in the agricultural sector. So it seems that Iranian farmers need to manage their electricity consumption to offer a competitive price for the crops. This is the original idea behind the evaluation of power system Type A.

\section{Intermittent-Supplied Power Systems}

In the power systems with high penetration of renewable power, i.e. wind energy, the power system may experience deficit/ excess of energy at any time of the day. In contrast to the power systems Type A, the peak time of the power system depends heavily on the wind velocity which is a stochastic variable. Therefore, the hour of peak time may be unknown up to $24 \mathrm{~h}$ prior to the energy delivery time. Approaching the energy delivery time, the uncertainty level decreases noticeably. In such power systems, the nature of ADRPs is different from those in power system Type A. The main reason is that the power system should be ready to send DR request to the contracted consumer in any time of the day. Therefore, ADRPs should be scheduled to provide power flexibility with different length of notices, from $24 \mathrm{~h}$ ahead to near real-time. The ADRPs for these power systems are more complex than the former power systems, i.e. Type A.

Figure 3 illustrates the peak of wind power generation for Danish sector of Nordic Electricity Market with approximately $50 \%$ wind power penetration. Based on the graph 3(a), the time of peak power generation cannot be conformed to a fixed pattern. In contrast to the power systems Type A, the time of peak generation is not under the control of the power system operator. As the subfigure 3(b) reveals, the peak generation of wind energy is a nonseasonal variable is not following a set pattern.

Regarding the abovementioned facts, this kind of power systems is called Type B. The future power systems will be bursting with renewable energy. Therefore, the ADRPs should be planned to guarantee the power system flexibility with high penetration of intermittent power. This is the novel idea behind the evaluation of power system Type $B$.

\section{Agricultural Electrical Demand}

In the agricultural sector, different sources of energy are used including electricity, gasoline, natural gas, oil, and diesel.

(a)

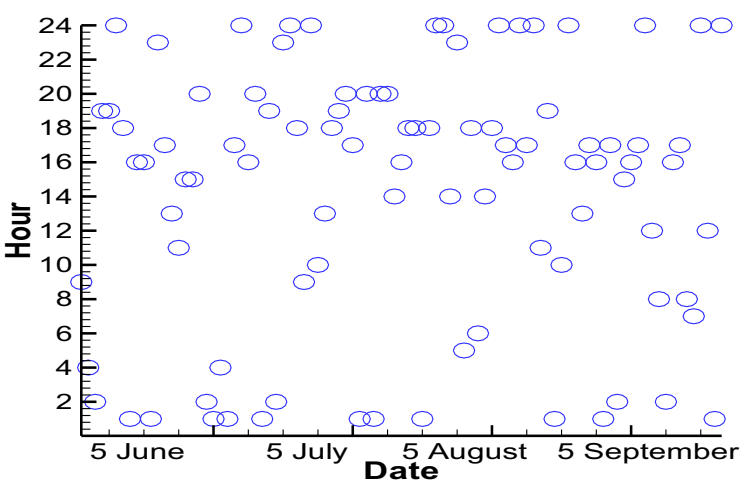

(b)

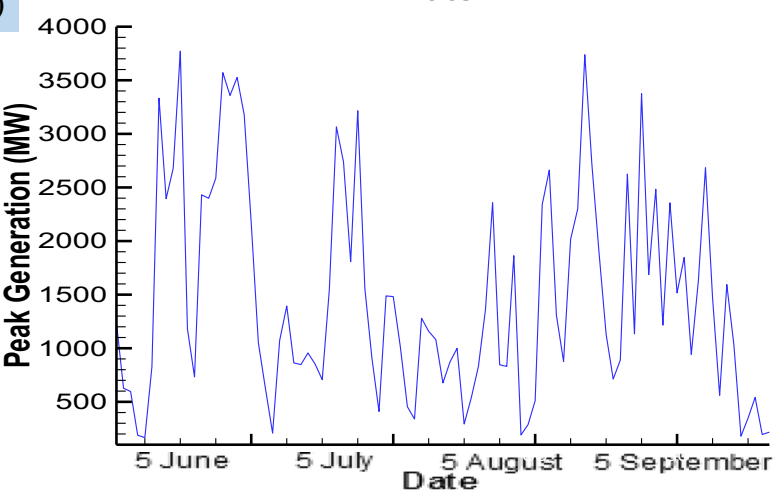

Fig. 3 Key features of DK1 (Danish Sector of Nordic Electricity Market) (a) Daily peak time of wind power generation (b) Daily peak generation of wind energy. The raw data is extracted from Nord Pool [28] which is publicly available. The data corresponds to date from 5 June to 5 September 2018 
According to the report from the U.S National Agricultural Statistics Service [29], the electricity, diesel and natural gas consumed 290, 410 and 150 Trillion Btu in 2014, respectively. The statistics confirm that electrical energy is one of the main energy types consumed in the agricultural sector. Apart from the different types of energy, this paper aims to propose consumption flexibility for electricity usage. To achieve the aim, first of all, it is shown how the electrical demand of the agricultural sector can be forecasted in the future. Secondly, the major electricity consumptions in the farms having DR capabilities are identified.

\section{Agricultural Load Forecasting}

Electricity demand forecasting is a challenging task in the agricultural sector where the ADRPs suffer from lack of required data and mathematical models. In order to propose a comprehensive ADRPs, the mid-term load forecasting of agricultural sector is essential and inevitable. Without a scientific forecasting approach, the ADRPs may be ineffective. In the last decade, many research studies were conducted to forecast the agricultural demand. Trend analysis is the simplest load forecasting approach [30]. This method relies solely on the historical load with no consideration of the factors that affected the amount of energy used. Although the simplicity is the main advantage, the method suffers from conspicuous lack of accuracy. Econometric models specify the relationship between the forecasting variable and the key factors affecting it by combining economic theory with statistical methods [31]. Improved accuracy and addressing the key factors affecting the forecasting variable are two distinct advantages of the method. But the method has a serious disadvantage that it is not able to address the decisive factors which change the future relationship between factors and electricity demand. It is the major barrier to DRPs where the future forecasting is necessary. Survey-based forecasts use information from a select group of customers regarding their future plans as the basis for the forecast [32]. In contrast to the econometric methods, this approach can take into account the considerable changes in the farms demand. The great disadvantage is that the method can forecast the changes only for short term durations. Therefore, the method is ineffective for mid/long term ADRPs.

The end-use methods [33] classify the electricity consumption of the agricultural sector into different categories. This method can change the energy efficiency of classified electrical devices; as a result, this is the practical approach for the Agricultural Energy Efficiency Measures. The negative point is that the method needs a huge amount of data to process. Therefore, the method is data-intensive while the electricity consumption of some agricultural devices may be unavailable. Recently, hybrid forecasting methods are used by the researchers taking the advantages of improving accuracy and flexibility. A new hybrid model based on improved empirical mode decomposition, autoregressive integrated moving average and wavelet neural network (WNN) optimized by fruit fly optimization algorithm is proposed recently [34]. As a practical study, a time series based on Auto Regressive Moving Average (ARIMA) approach is used in paper [35] to forecast the Iranian agricultural electricity consumption. To provide a quick overview of the agricultural load forecasting methods compatible with ADRPs, Fig. 4 illustrate the important pros and cons. As the pie chart reveals, the hybrid forecasting approaches provide the greatest flexibility among the traditional load forecasting methods.

\section{Agricultural Electricity Consumption}

Investigating flexibility potentials in the agricultural sector, it is crucial to understand the consumption behavior of electrical devices. To fulfill the aim, first of all, it is necessary to know the application of electricity on farms. Generally, the application of the on farms can be split into four major categories as (1) farm building (2) farm land (3) crop treatment and (4) farm house. Figure 5 illustrates the classification of the application of electrical energy to farms.

As the circle diagram reveals, the electricity consumption on the farm buildings depends on the type of agricultural activity. In the livestock farms, the food preparation devices, e.g. chuff butters and corn crushers, consumes electrical energy. In the dairy farms, most of the devices are electric driving like the cream separator and casein grinders.

Regarding the farm land, irrigation system consumes a large amount of energy. In addition, some electrically operated machines, e.g. mower and digger, are used during harvesting and planting.

Crop treatment refers to measures taken to avoid damage of crops insect, seed or environmental factors. Electrolytic seed bath and electrical heat-treatment of seeds are two kinds of measures in the seed preparation. Gathering the crops, grain drying and desiccation of vegetables/fruits by electric fans can be stated.

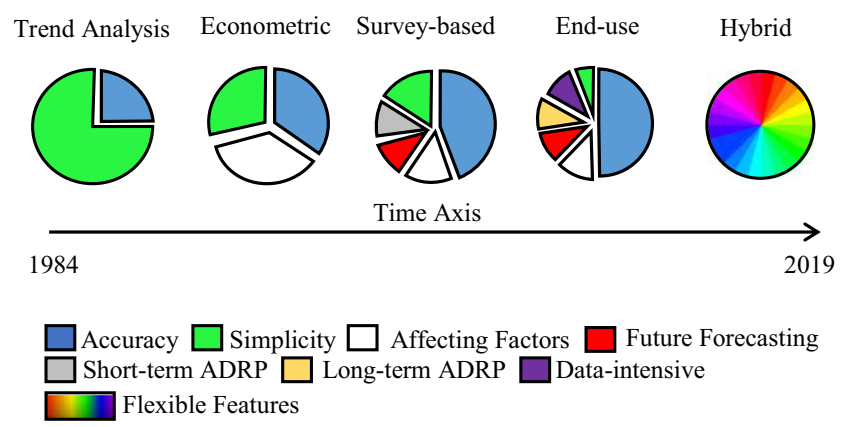

Fig. 4 The compatibility of agricultural load forecasting approaches with ADRPs from 1984 to 2019 with significant features 
Fig. 5 The general classification of electricity consumptions on farms

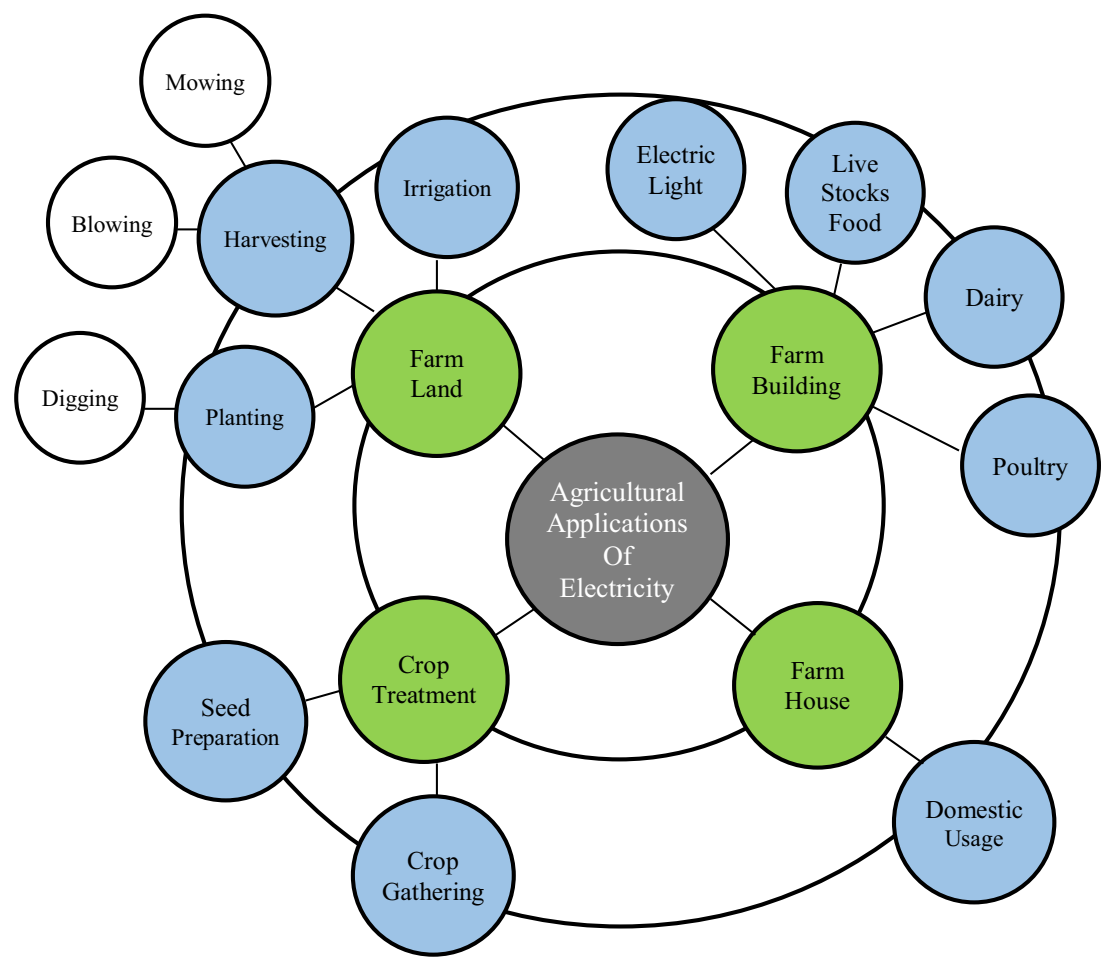

The electrical demands on the farm house can be considered as domestic electrical power usage. Cooling, heating, and cooking are the main electricity consumptions in the farm houses.

The electricity consumptions on farms are not limited to the abovementioned classification. The electrically operated devices on farms are widespread and the providing detailed description is outside the scope of this study. In order to investigate the ADR flexibilities on farms, certain electrically operated devices should be studied. Among the electrical devices, the irrigation system consumes a large amount of energy on farms. Therefore, this study investigates the DR opportunities for irrigation systems on farms. One may conduct a research study to investigate DR opportunities in dairy or poultry farms. This can be an innovative idea for future researches. All in all, the main electricity consumption of irrigation system is described in the following subsections.

\section{Agricultural Irrigation System}

Irrigation systems are the most energy-intensive consumption on farm lands. The irrigation system moves water from a resource or storage to the crops. Water pumps are the heart of irrigation systems. To make an irrigation system as efficient as possible, the pump must be selected to match the requirements of the water source, the water distribution system and the irrigation equipment.

Water pumps consume a large amount of electrical energy in agricultural demands. Based on the irrigation methods and local characteristics of the farms, the water pumps used in conventional farms can be divided into four main categories as follows:

1) Groundwater pumps (GWP)

2) Surface water pump (SWP)

3) Water booster pump (WBP)

Figure 6 depicts a schematic diagram of the irrigation system in agricultural lands. The groundwater pumps lift water from a bore to the agricultural lands. The nominal electricity consumption of the GWPs depends on the characteristics of the wells. Generally, this kind of water pumps can be designed for three main wells as follows: (1) deep wells (2) moderate wells and (3) shallower wells. In the north of China, the average annual energy consumption for groundwater pumping is 13.67 billion $\mathrm{kWh}$ and the energy consumption is $1122.4 \mathrm{kWh} / \mathrm{hm}^{2}$ in 2019 [36]. The energy intensity of GWPs ranges from 250 to 1000 $\mathrm{kWh} / \mathrm{AF}$ with an average of $500 \mathrm{kWh} / \mathrm{AF}$ [22].

Surface water pumps are used to move water from surface water resources to the irrigation system of the farms. The average energy intensity of SWPs is around $300 \mathrm{kWh} / \mathrm{AF}$ which is $40 \%$ lower than the GWP ones [22].

Booster pumps are the heart of the irrigation system which increases the pressure of water. The energy intensity of WBPs range from 0 to $14 \mathrm{kWh} / \mathrm{AF}$ for gravity irrigation, 147-269 $\mathrm{kWh} / \mathrm{AF}$ for drip/micro irrigation, and 217-342 $\mathrm{kWh} / \mathrm{AF}$ for sprinkler irrigation [15]. 
Fig. 6 Agricultural irrigation system with GWP, SWP and WBP

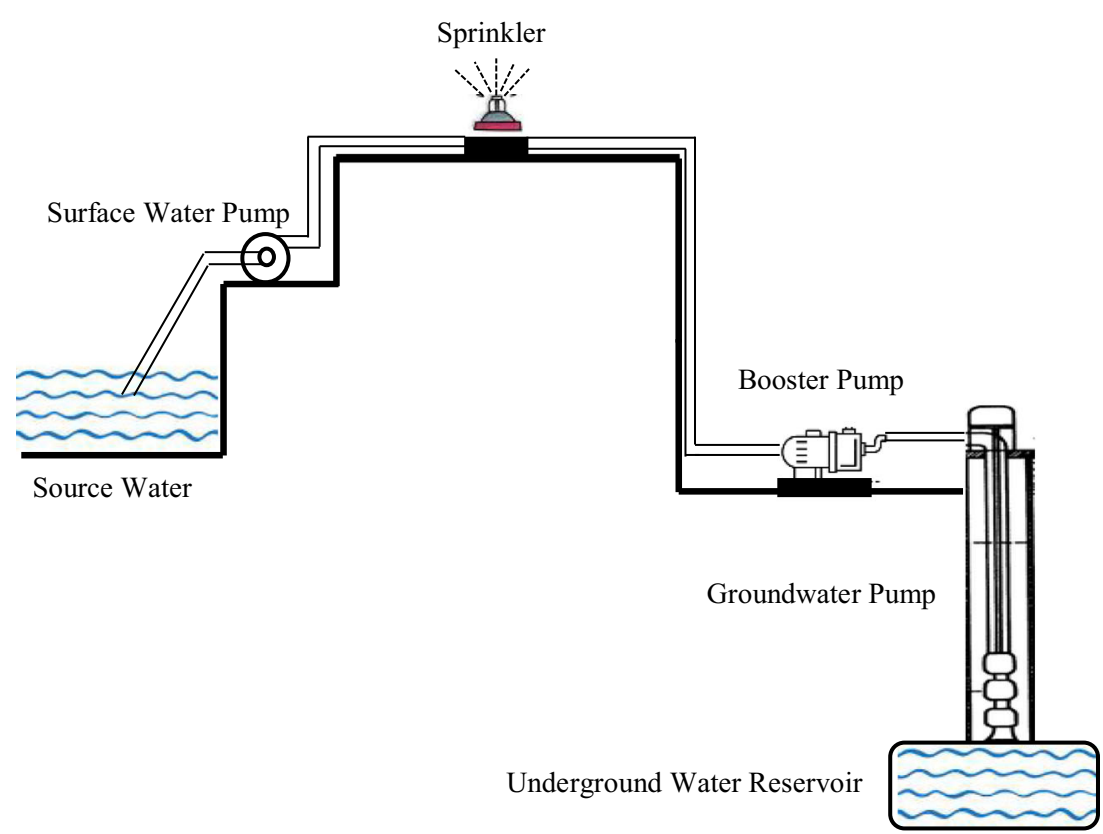

Comparing the water pumps, the GWPs are the most energy-intensive devices. Moreover, the investment and operation costs of GWPs are higher than the SWP and WBP, especially for the deep wells.

\section{Agricultural Demand Side Management}

Agricultural Demand Side Management (ADSM) refers to initiatives and technologies which optimize electrical energy consumptions of farms. In the ADSM, both software and hardware optimizations are included. The software ADSM refers to the plans/schedules causing a behavioural change in electricity consumption. In contrast, the hardware ADSM addresses the measures introduced to increase/decrease the energy efficiency/intensity of electrically operated devices. Based on the abovementioned facts, the ADSM can be implemented into three main categories:
1) Agricultural Energy Efficiency Measures (AEEM)
2) Agricultural Permanent Load Shifting (APLS)
3) Agricultural Demand Response Programs (ADRP)

Regarding AEEM, energy efficiency solutions should be suggested. While the electric motors consume a large amount of energy in the irrigation systems, the efficient electric motors decrease the energy intensity of the irrigation system. In order to optimize the energy efficiency of motors, the following measures are offered [37]:

1) Considering the relation of size and efficiency: For optimum efficiency, motors should be sized to operate with a load factor between $65 \%$ and $100 \%$. Oversizing results in less efficient motor operation.

2) Comparing the efficiency of motors: Nominal efficiency is best. Nominal efficiency is an average value obtained through standardized testing of a population of motors. Minimum guaranteed efficiency, which is based on nominal efficiency, is slightly lower to take into account typical population variations. Minimum guaranteed efficiency is also less accurate because the value is rounded. Other efficiency ratings, including apparent and calculated, should not be used. High-efficiency 3-phase motors are designated as "Premium Efficiency" motors and are 2 to $4 \%$ more efficient than a standard motor.

3) Using Variable Speed Drives (VSD): Variable speed drives on electric motors can save considerable energy on farms. A standard motor has two speeds, full power or completely off. VSDs are capable of running at the needed power rating for the given task and adjusting speed to match the conditions. Utilizing VSDs can reduce electricity use by $60 \%$ sometimes more.

4) Carrying out regular inspection/maintenance: Electric motors are generally a low maintenance piece of equipment but there are a few simple things that can be done to ensure efficient and reliable operation. Removing dust and dirt from the motor enclosure, cleaning air cooling systems, lubricating motor bearings and correcting the alignment of motor shafts are the most important measures should be taken to increase the energy efficiency of motors.

Apart from AEEM which is a hardware ADSM, there are two software types including APLS and ADRP which are in 
the greater scope of this study. The APLS is perfectly suitable for the power systems with known peak duration, i.e. Type A, e.g. IPS. The APLS can be determined on long notice to reduce the peak load of the grid. Time-based electricity pricing is the best strategies for APLS. Time of Use (TOU), Critical Peak Pricing (CPP), Extreme Day Pricing (EDP) and Extreme CPP are the practical suggestions to the agricultural sector.

ADRPs are necessary for the power systems with a large portfolio of renewable energy, i.e. Type B. In such a system, real-time pricing is adopted in the electricity market to hedge against the renewable power intermittency. In this way, the new kinds of ADRPs need to be suggested to provide ancillary services to the electricity market. Regulation, replacement reserve, and contingency reserve are the most important DRPs providing ancillary services to the power grid. The ancillary service DRPs have response time from $30 \mathrm{~min}$ to a few seconds. Therefore, in the agricultural sector, the responsive demands should be classified based on the response time to the DR request. To achieve the aim, first of all, the technical challenges to ADRPs are illustrated. Afterward, the workable solutions are provided to overcome/lower the barriers.

\section{Barriers to ADRPs}

In order to suggest practical DRPs to the agricultural sector, it is needed to know the main barriers to DRPs. The barriers are classified into three main categories as follows:

1) Technical barriers of growers

2) Financial barriers of regulatory

3) Technical barriers of grid

In the following subsections, the main concerns are addressed.

\section{Irrigation Capacity}

The main aim of irrigation systems is to maintain the soil moisture to meet the water requirements of the crops. It is evident that different crops have different water requirements. Therefore, the size of the irrigation system depends mainly on the type of crops. There are three attitudes to design irrigation systems:

1) undersized irrigation systems: This irrigation system needs to be run continuously (24/7) to meet the crops water requirements.

2) oversized irrigation systems: This irrigation system has excess capacity in spite of the crops water requirements.

3) standard-sized irrigation systems: This irrigation system can meet the evapotranspiration peak of crops without needing to run continuously.
The main reason for under-sized design is the high cost of irrigation systems. The standard-sized irrigation system is designed to compensate for the rate of evapotranspiration in the hot hours of summer days. The oversized irrigation systems provide more moisture to soil than the highest value of evapotranspiration.

The undersized irrigation system is not designed properly relative to water requirements of crops in the highest evapotranspiration duration. This kind of irrigation system has to works near continuously without interruption; therefore, it is the main barrier to the DR events. The standard-sized systems can respond to the DR signals even in the summer.

\section{Time of Water Delivery}

Generally, pumping water from an irrigation district is done according to a prescheduled timetable. In this way, the irrigation of one farm cannot be changed without disturbing the irrigation timetable. Moreover, interrupting water delivery for limited farm lands, technical problems may be created for the water distribution system.

\section{Irrigation Source}

The farms are irrigated by the on-farm water resources or an irrigation district. The on-farm water resources, e.g. on-farm groundwater, has the highest flexibility to respond to the DRPs. In contrast, the farms supplied from a district has the lowest flexibility. In this way, the ADRPs impose inconvenience and additional cost to the growers due to disturbing the time of water delivery.

\section{Irrigation Method}

Broadly, there are four main methods to irrigate the agricultural lands as follows:

1) Gravity (flood) Fed Irrigation Systems (GFI): The GFI system is a cost-effective way to flow water from an elevated reservoir with a pipe coming out the bottom that feeds water into a basic drip irrigation system. The GFI is based on natural gravity.

2) Sprinkler Irrigation (SI) Systems: In the SI system, water is distributed through a system of pipes and sprayed into the air through sprinklers similar to natural rainfall.

3) Low-Flow Irrigation (LFI) Systems: the LFI is an irrigation method to distribute irrigation water slowly in small volumes and targeting it to plants' root zones through small flexible tubes. This system is called also low volume irrigation, micro/drip irrigation, and micro sprinkler.

4) Subsurface Drip Irrigation (SDI): The SDI is a highly efficient irrigation system that applies water 
below the soil surface (as opposed to surface irrigation) using drip tapes [38].

In the irrigation methods, there are two conflict objectives in term of electricity and water consumption. The GFI system has the lowest energy intensity and the highest level of water consumption. In contrast, the LFI system is the most energyintensive and the most water-efficient irrigation system.

In order to make a comparison between the irrigation systems from the viewpoint of interruption compatibility, it is worth mentioning that the GFI is the most incompatible irrigation system. Although this system is the lowest energy-intensive, irrigation interruption in response to the DR signals may result in poor irrigation. The reason is that the land sections closer to the water tank receive more water than further ones. The SI, LFI, and SDI ensure functional compatibility with the DR events.

\section{Crew Availability}

The on-site labor is one of the major barriers concerning the smart-level of the farm. Depending on the on-site labor, the flexibility of the farm to respond to the DR signals reduces noticeably. The main reason is that the interruption in the irrigation may cause the growers to reschedule or extend the working hours of the labor. Therefore, an additional cost is imposed on the farm owners and inconvenience is caused.

\section{Communication System}

Generally, the remote control is the initial step to smart farming. The essential characteristic of smart farming, like any other smart energy system, is the two-way communication system. In the agricultural sector, most farms suffer from lack of communication systems. One reason is that the agricultural lands are located mostly in rural areas is not covered by the signals of conventional communication systems.

\section{Financial Incentive}

Responding to the DR requests, additional costs are imposed on the agricultural sector. In this way, if the financial loss is not compensated by the beneficiary entities, e.g. power system operator, the farm owners may be unwilling to participate in the ADRPs. The main concern is how much financial incentives should be offered to the farmers to make the ADRPs compelling. Generally, the additional costs can be the result of the following cases:

1) Flexible schedule of irrigation and labors' working hours.

2) Aging cost of electrical machinery due to unplanned startup and shut-down.

3) The attendant risk posed to the crops quality.
The extra cost imposed to the growers should be covered by the upstream entities which are the main beneficiaries of the ADRPs.

\section{Distribution System}

Agricultural distribution feeders are normally located in the rural area supplying the contracted farms. These kinds of feeders are designed based on the consumption behaviour of agricultural electrically operated devices [39]. While most agricultural devices are electric motors, the voltage variations, e.g. overvoltage and undervoltage, is the main concern. Implementing ADRPs, a large number of electric motors may be concentrated on certain hours out of DR events. Therefore, the ADRPs may deteriorate the power quality of the distribution feeders.

To sum up, Fig. 7 illustrates the barriers of the ADRPs with respect to growers, distribution network and power system regulator.

\section{Solutions to ADRP}

In this section, practical solutions are suggested to remove or lower the barriers to ADRPs. To achieve the aim, the
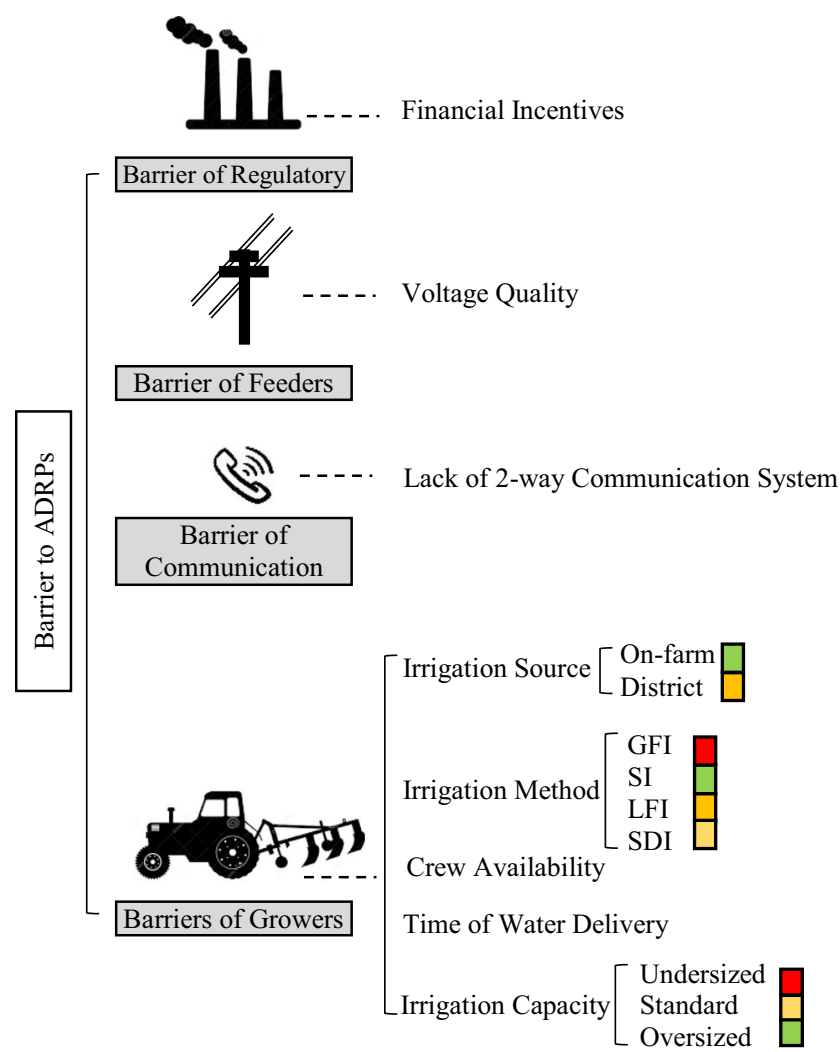

Fig. 7 The major barriers to the ADRPs. The colour box describes the compatibility to the DR events with alow, amoderate and ahigh compatibility 
workable solutions are provided for each barrier individually. Moreover, mathematical formulations are proposed in some sections to make the solution perfectly clear.

Investigating DR opportunities, the basic idea is to find out what kinds of storage capabilities are hidden in the consumption behaviour of the consumers. In the agricultural sector, the most electrical energy is used in the irrigation system to maintain the soil moisture within a permitted bound. Therefore, the soil moisture is a valuable storage capability which can provide power flexibility to the power system. In this way, the ADRPs should be coordinated with the growers to irrigate farms out of DR events meeting the water requirements of crops during DR implementation.

\section{Solution to Time of Water Delivery}

In order to overcome the tight schedule of water delivery, two alternative solutions are offered as follows:

1) Rescheduling the timetable of water delivery for the whole irrigation district instead of limited farms. In this way, no inconvenience is caused due to interruption on water delivery.

2) Installing a water reservoir to store water and irrigate the crops in the off-peak hours. In this way, if an overhead tank is used as the water reservoir, the main electricity consumption will be shifted to the off-peak hours. In fact, the overhead tank irrigates the farms with gravity without needing the electrical energy. In this way, the electrical energy is used to draw water from a surface/underground water resource to the overhead tank out of peak hours.

\section{Solution to Communication System}

As mentioned above, the farms located in the rural area suffer from lack of communication system. Effective ADRPs need a secure 2-way communication system. However, conventional communication systems may cover some agricultural lands, the active ADRPs require reliable and fast communication. In this way, the security of data is a serious challenge [40]. To eliminate the barrier, an Agricultural Communication Service Provider (ACSP) is a practical suggestion to provide two-way communication between farm owners and ADRA. The Power Line Career (PLC) may be used for some farms near the rural transmission towers. Figure 8 describes the difference between the conventional communication systems and ACSP in urban and rural areas, respectively. In the structure, the Farm Central Unit (FCU) is a part of communication system receiving the DR signals and sending the DR responses to the ADRA or system operator.

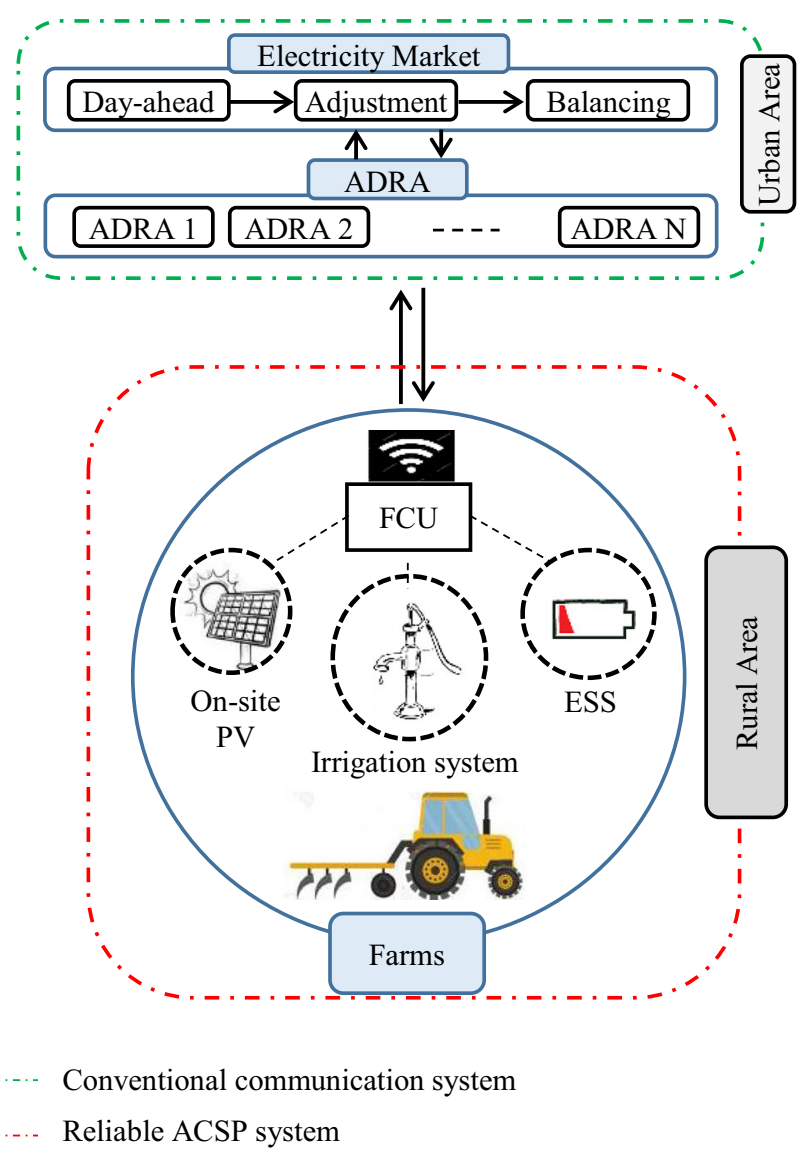

Fig. 8 The territory of conventional communication system and suggested ACSP

\section{Solution to Financial Incentives}

Generally, incentives-based DR programs is a workable solution to motivate consumers to participate in DR programs or compensate for the lack thereof [41]. Regarding the financial barrier, three costs are imposed on the growers including the costs associated with excess working hours, crops quality and irregular operation of electric machines. In order to make the growers compelling to participate in the ADRPs, a financial intensive should be allocated to the contracted farms. To reduce the concern for the value of the intensive, the average cost imposed on the farmers should be investigated. Therefore, mathematical formulations are suggested to provide detailed analysis to the policy-makers.

Regarding the crew constraints, any interruption may cause an extension of the working hours for the labors. Therefore, rescheduling the agricultural activities to provide demand flexibility to the power system, an additional cost imposed on the growers. In order to address the cost in the determination of financial incentive, the crew constraint can be formulated as follows:

$C^{l}=\sum_{i=1}^{I} \sum_{\beta=1}^{B} C_{i, \beta}^{l}$ 
$C_{i, \beta}^{l}=t_{i, \beta}^{\Delta} \times \mathrm{K}_{\mathrm{labor}}$

Equation (1) describes the total cost imposed on the farms due to the extension of working hours. Equation (2) shows the additional cost imposed on the farm for ADR duration $t^{\Delta}$ (hours) for one on-site labor.

In the case of irrigation, an interruption may result in water loss/overuse. In many crops, crop price is variable and dependent on yield quality e.g., water irrigation. Some research studies are carried out to extract a mathematical function to describe the relation of crops price and water limiting conditions [42]. The mathematical formulation enables the growers to strike the right balance between risk and profit. Moreover, it helps the policy-makers to determine a fair mechanism to the financial incentives. In 2016, a mathematical formulation is extracted for sugar beet yield in the western agricultural lands of Iran as follows [43]:

$\mathrm{P}_{\mathrm{c}}=\mathrm{a}_{1}(\theta+\rho)^{2}+\mathrm{b}_{1}(\theta+\rho)+\mathrm{c}_{1}$

$\mathrm{C}_{\mathrm{p}}=\mathrm{a}_{2}(\theta+\rho)^{2}+\mathrm{b}_{2}(\theta+\rho)+\mathrm{d}_{1} \theta+\mathrm{c}_{2}$

$\mathrm{E}_{\mathrm{p}}=\left[\mathrm{a}_{3}+\mathrm{b}_{3}(\theta+\rho)\right] \times d_{2}$

where $a_{1}, a_{2}, a_{3}, b_{1}, b_{2}, b_{3}, c_{1}$ and $c_{2}$ are constant. $d_{1}$ is the water cost $\left(\$ \mathrm{~m}^{-3}\right)$ and $\mathrm{d}_{2}$ is the price of unit weight of sugar beet $\left(\$ \mathrm{~kg}^{-1}\right)$ with sugar content $16 \%$.

Equation (3) describes the production value of crops $\left(\mathrm{kg} \mathrm{ha}^{-1}\right)$ in term of applied water for both irrigated and rain water. Equation (4) illustrates the relationship between the production cost of the crop $\left(\$ \mathrm{~kg}^{-1}\right)$ and applied water. The relation between crop price and the applied water is stated by Eq. (5). The constant values are in accordance [43].

Considering the irregular operation of electric machines, the cost of start-up/shut-down of electrically operated motors, e.g. irrigation pumps, is the main part of additional costs which should be met by the beneficiaries of ADRPs. According to the datasheet of electrical pumps, there is a limited number of start-up/shut-down between two failure states. Therefore, responding to the DR events, the possibility of failure increases due to irregular motor switching. In order to identify the failure cost of motors, Markov Chain Model is used [44]. Figure 9 depicts the Markov chain to model deterioration, failure, and maintenance for electrical water pumps. In this model, $\mathrm{F}_{0}$ and $\mathrm{F}$ are random failure and failure due to deterioration, respectively. $\mathrm{K}$ is discrete steps. The time spent in each stage of deterioration is exponentially distributed with an identical mean of $1 / \kappa \lambda_{1}$. Maintenance is modeled as a Poisson process with a parameter $\lambda_{\mathrm{m}}$. Maintenance times are exponentially distributed with a mean of $1 / \mu_{\mathrm{m}}$.

Regarding the Markov model, the cost of irregular operation for the electrically operated motors can be formulated as follows:

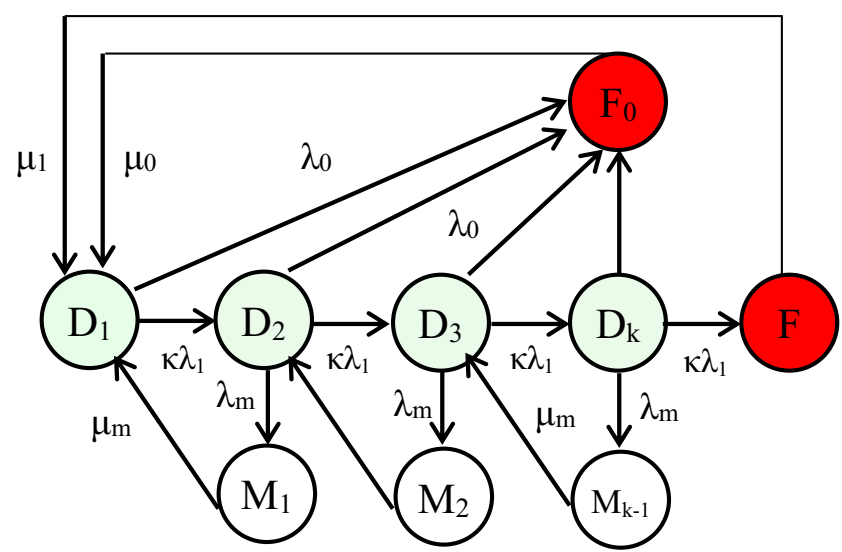

Fig. 9 Markov chain with deterioration ( $D$ state), failure $(F$ state $)$ and maintenance ( $M$ state) states

$$
\begin{aligned}
C^{m} & =\sum_{i=1}^{I} \sum_{\alpha=1}^{A} C_{i, \alpha}^{m} \\
C_{i, \alpha}^{m} & =\left(\pi_{1} \times \frac{\gamma_{i, \alpha}}{\nu_{i, \alpha}^{\max }}\right)+\left(\pi_{0} \times \gamma_{i, \alpha}\right)=\left(\frac{\gamma_{i, \alpha}}{\nu_{i, \alpha}^{\max }}\right) \times\left(\pi_{1}+\nu_{i, \alpha}^{\max } \pi_{0}\right)
\end{aligned}
$$

Equation (6) states the total aging cost of motors. The aging cost for one electrical pump is expressed by Eq. (7). The aging cost Eq. (7) is comprised of two terms. The first term describes the cost of discrete deterioration and the second term expresses the cost of random failure.

In this section, three costs are considered. However, one may extend the study and address more costs imposed on the farms due to DR events. All in all, the financial incentive should cover the estimated cost:

$C^{F I} \geq C^{l}+C^{m}+\left(\Delta C_{p}+\Delta E_{p}\right)$

where $\Delta \mathrm{C}_{\mathrm{p}}$ and $\Delta \mathrm{E}_{\mathrm{p}}$ refer to the increased production cost and decreased crop price due to participation in ADRPs, respectively.

\section{Solution to Irrigation Capacity}

The best DR potential is for the irrigation system without needing to be run continuously (24/7). The irrigation system has an Evapotranspiration (ET) peak which occurs in the midday of hot summer days. on the other hand, the power system has its own peak time. If the peak of the power system coincides with the peak of the irrigation system, the under-sized irrigation systems cannot respond to the ADRPs effectively. This issue occurs for the power system Type A. A workable solution it to redesign the irrigation system to switch from under-sized system to standard one.

In contrast, if the peak of the power system does not coincide with the evapotranspiration peak of farms, the irrigation system has an excess capacity which can be used to provide demand flexibility to the power system. This problem occurs in the power system Type B where the peak of the grid does 
not necessarily occur in the summer in coincident with the evapotranspiration peak. Figure 10 depicts a schematic diagram to describe the peak of evapotranspiration and electricity demand for two types of power systems.

\section{VSD Pumps}

The VSD pumps can provide ancillary service and regulation to the power system in DR events with short notices. The VSD pumps play a crucial role in providing demand flexibility to the power system with high penetration of renewable power, Type B. The distinguishing characteristic is that they can respond to the DR event on short notice which is necessary for power system Type B. The VSD pumps can respond to dynamic pricing of electricity market or near real-time DR. On the other hand, the VSD pumps reduce the aging cost of the electrical pumps without needing to shut down and start-up. Providing soft start/stop to the pumps and reducing the stress on the well are significant features of VSD pumps.

\section{On-Farm Renewable Power Generation}

On-farm power generation from renewable resources is a practical solution to the ADRPs. Without urban context, the agricultural lands are appropriate locations to renewable power generation, especially wind and solar.

The on-farm solar power generation is highly appropriate to the power system Type $A$ where the peak of solar generation coincides with the peak of the power system at midday summer. Moreover, the farms are located in rural areas without shading of urban contexts such as trees or neighbouring buildings. Therefore, it can increase the efficiency of solar power generation.
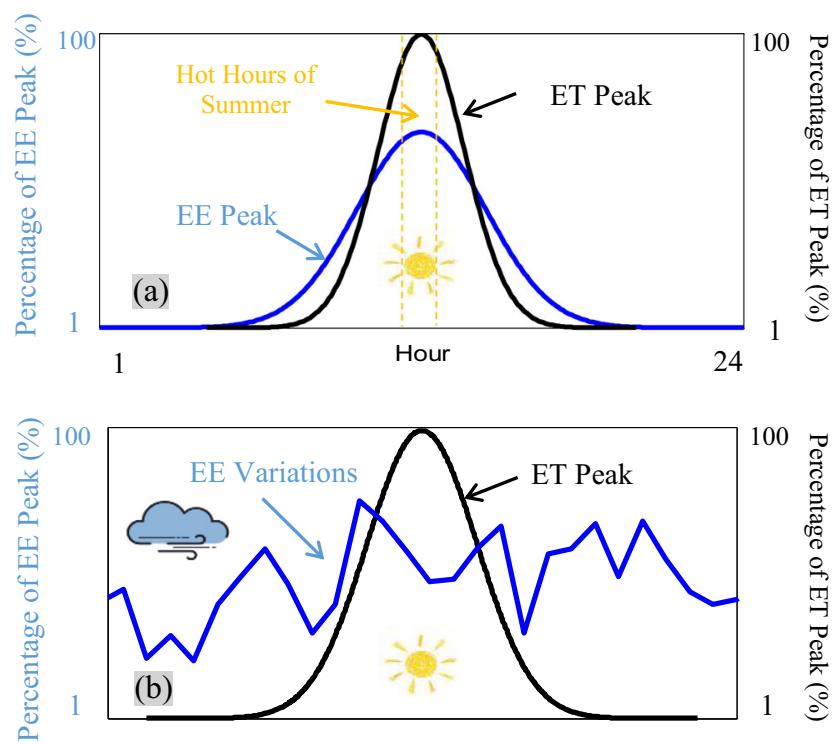

Fig. 10 Comparison of Electrical Energy Peak (EE Peak) and Evapotranspiration Peak (ET Peak) for power systems (a) Type A and (b) Type B
In contrast to the solar sites, the on-farm wind power generation is extremely effective to the power system Type $B$ where the peak of the power system is a stochastic variable and coincides with the peak of on-farm wind power generation.

\section{Photovoltaic Pumps}

The use of photovoltaic (PV) pumps is a real and quick solution for the power systems Type A which suffer from a lack of power generation at midday hours of summer. The peak generation of PV pumps coincides with the ET peak of farms and EE peak of the grid. Therefore, they are the best solution as an APLS.

The PV pumps are fed from photovoltaic panels. In spite of the electrical-mechanical structure of the conventional pumps, the PV pump system is comprised of the additional power electronic devices as follows: (1) PV panels (2) converter (3) inverter (4) a controller for converter/inverter [45]. The additional controllable devices increase the flexibility of the pumps in the ADRPs. As a result, the PV pumps are compatible with both APLS and ADRP. The main concern is shading or partial shading due to soiling and clouds which are causal in rural lands.

\section{Solution to Crops Value}

Implementation of DRPs in the agricultural sector, the crops quality may be affected if the water requirements are not met completely. In order to remove the concern, the value of crops should be considered in the ADRPs. Generally, from the viewpoint of crop quality, there are two types of crops: (i) high-value crops and (ii) low-value crops. The high-value crops, e.g. vineyard, refer to agricultural products which the electricity price is a small fraction of the crop price. Adversely, in the low-value crops, e.g. hey, the cost of electrical energy is a large fraction of crop price. It means that the growers of high-value crops prefer not to put their valuable crops at risk for a few dollars. Adversely, the growers of low-value crops are willing to respond to the DR request because of considerable money-saving. Therefore, to make the ADRPs highly successful, the farms with low-value crops should be a high priority and vice versa. In order to incorporate the value of crops into the ADRPs, a new criterion, called Risk to Benefit Ratio (RBR), is suggested in this study as follows:

$\eta_{\kappa}=\frac{\text { Risk }}{\text { Benefit }}=F\left(\frac{C_{e}}{C_{p}}\right)^{-1}$

The crops are classified based on the criterion $\eta_{\kappa}$. The fields with low $\eta_{\kappa}$ are high priority than the fields with high values.

In order to make the problem clear, Fig. 11 describes the share of electricity cost as a percentage of total production cost for some farms. Moreover, the associated RBR values are calculated to investigate the priorities to the ADRPs. 
The step-by-step instruction to determine ADRPs with respect to the crops value is illustrated in Instruction Box 1. This instruction provides guidance for the beneficiaries of ADRPs to motivate the growers to respond to the DR events.

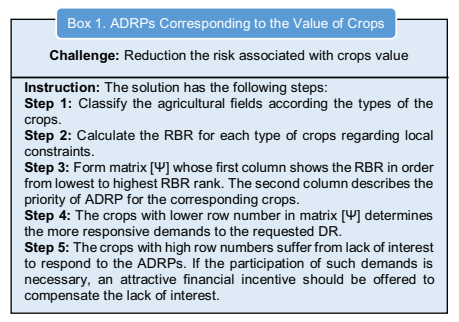

\section{Solution to on-Site Crew}

In order to reduce the labor barrier, a remote control is a practical suggestion. The remote control reduces the number of on-site labors to manually switch off/on the irrigation systems. It needs to upgrade the current equipment and installs new equipment. It is worth mentioning that many growers may be unwilling to install remote control. The main reason is the high investment cost of equipment. To compel the growers to install remote control devices, governmental financial support is a helpful suggestion. The main beneficiaries of ADR, e.g. power system operator, may allocate a supportive budget to shift the financial burden toward the governmental entities. In order to control the agricultural lands by an aggregator remotely, an instruction is suggested in Instruction Box 2.

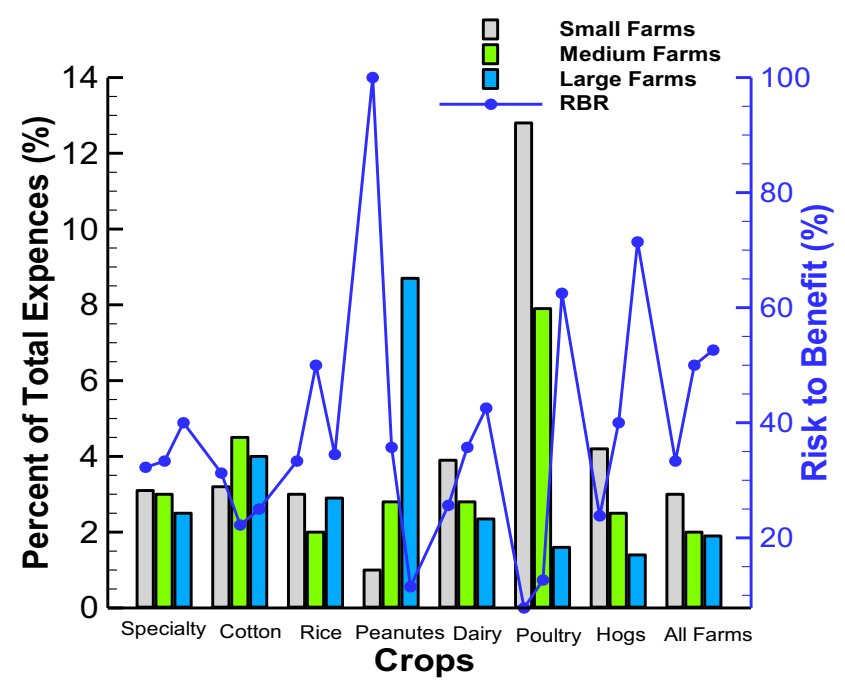

Fig. 11 The share of electricity cost as a percentage of total production cost for some farms. The raw data is extracted from the National Agricultural Statistics Service (NASA) [46]

\section{Agricultural Demand Response Aggregator}

In the previous sections, the main barriers to the ADRPs were illustrated. Afterward, practical solutions were suggested to break the barriers. Responding to the DR events, individual demand flexibilities cannot satisfy the power system requirements. In other words, the power system needs aggregated demand flexibilities instead of segregated ones. In this way, if the flexibility potentials of agricultural lands are aggregated properly, the resultant flexibility can guarantee the power system flexibility when power shortage occurs or system reliability is jeopardized.

Generally, The Energy Information Administration (EIA) [47] defines an aggregator as a marketer, broker, public agency, city/county/special district that combines loads of multiple end-use customers in facilitating the sale and purchase of electrical energy, transmission, and other services on behalf of the customers. The ADRA is defined as a grid-dependent entity who gives the contracted farms the opportunities to know their demand flexibility on one side and integrate the aggregated flexibility potentials to the power systems. It is evident that the structure and duties of ADRAs depend heavily on the type of power system in term of penetration of intermittent power.

In this section, a practical structure is proposed for the ADRA. Breaking the barriers to ADR programs, the farm flexibilities should be aggregated to meet the power system requirements. To achieve the aim, a workable solution is proposed for the ADRA to facilitate the integration of farm flexibilities to the power system. In the suggested structure, the ADRA uses three trading floors in the electricity market to integrate demandside flexibility with different response time, from $24 \mathrm{~h}$ prior to energy delivery time to near real time, to the electricity market. This is one of the main contributions of the study to suggest a new intermediary entity between supply-side and agricultural-side.

ADRPs suffer from a lot of challenges and barriers. Therefore, a wide gap exists between the ADRPs, power system and agricultural consumers. In order to narrow the gap, a third party entity, i.e. ADRA, is needed to remove the barriers, motivate the farmers and market the ADRPs to the growers. Figure 12 depicts the role of suggested ADRA in the power system as an intermediary agent. In the next subsections, a mathematical structure is proposed for the ADRAs.

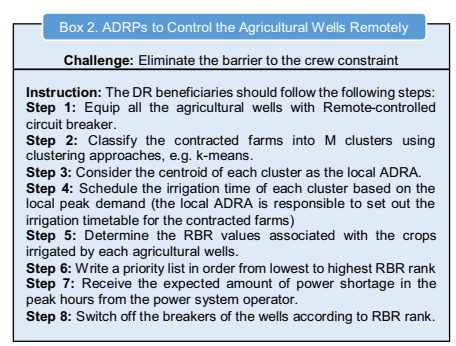




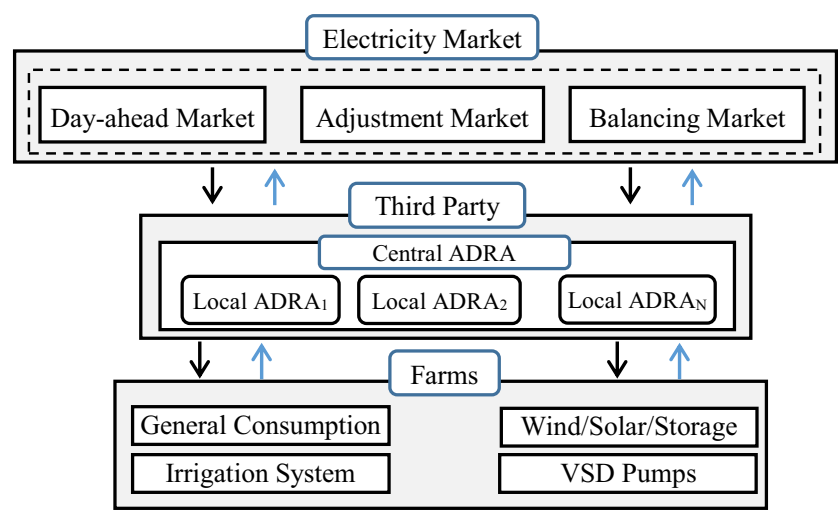

Fig. 12 Framework of ADRA as an intermediary entity in the power system

\section{ADRA to Power System Type A}

In the power system Type A, the electricity price is the single uncertain variable. There is no power intermittency due to renewable energies. One may consider the demand level as the second uncertainty. However, there is a strong correlation between demand and electricity price. In such a power system, the satisfactory solution is to optimize the problem under the worst-case realization of the single stochastic variable. To achieve the aim, robust-based solution methodologies are suggested. The robust approaches are efficient in time and calculation burden of the problem in comparison with the stochastic techniques which suffers from complexity and a heavy time burden of computations.

In order to motivate the growers to shift the power consumption out of DR events, the ADRA incorporates timebased DRPs, i.e. TOU, CPP, and ED-CPP, to the electricity market. Increasing the electricity price in the DR durations, a considerable amount of electricity consumptions is shifted out of peak hours.

\section{ADRA to Power System Type B}

The power system Type $B$ is overwhelmed by uncertain variables. The power intermittency of renewable resources, e.g. wind and solar energies, are the key stochastic variables. In this way, a clear correlation cannot be found between electricity price, demand level, and renewable power. The main reason is that renewable power follows the environmental factors while the electricity consumption of consumers has its own sociodemographic characteristics. In such a power system, stochastic programming is an effective solution. The compelling reason is that stochastic programming makes it possible to study the problem under severe uncertainties associated with more than one stochastic variable.

Figure 13 shows how the ADRA Type $B$ facilitates participation of different farm equipment in the ADRPs, from 24-h ahead to near real-time. In this structure, the power traded in the day-

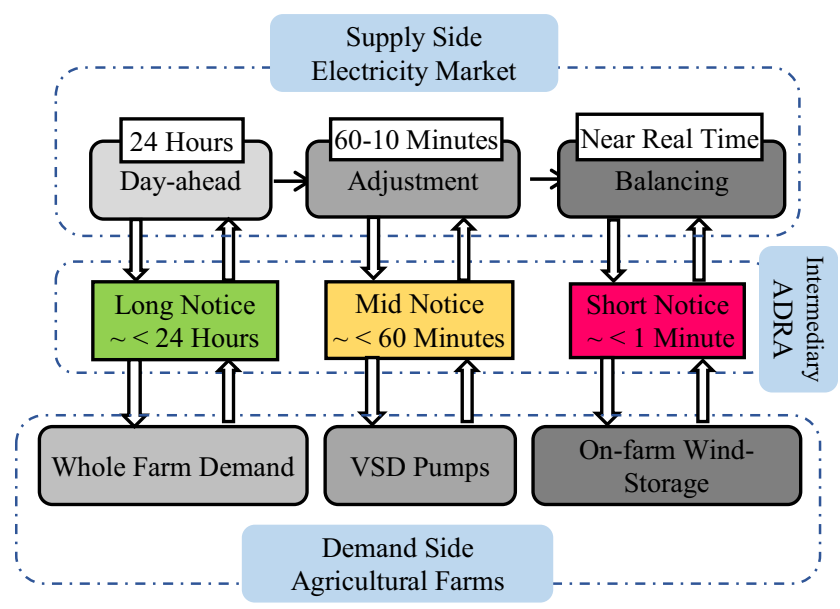

Fig. 13 Time-oriented ADRPs from $24 \mathrm{~h}$ ahead to near real time

ahead, adjustment and balancing markets should be restricted. In this way, the power purchased from the day-ahead market is restricted to the sum of energy consumption in the irrigation system of the farms which can be scheduled $24 \mathrm{~h}$ prior to the energy delivery time (long notice-based DR programs). The power traded (purchased/sold) in the adjustment market is restricted to the electricity consumption of VSD pumps which can be switched off/on 60 to $10 \mathrm{~min}$ prior to the energy delivery time (mid notice-based DR programs). In this market, the conventional electric pumps (without VSD) cannot participate in the DR programs. The reason is that conventional pumps cannot change the electricity consumption without switching, i.e. regular startup/shutting down. Implementing DR programs on the conventional pumps, a heavy financial loss may be imposed on the equipment/crops due to damages to the electric motors/crops quality. The power traded (purchased/sold) in the balancing market is limited to the energy injection of the wind-storage systems with the ability to change power within a few minutes (short notice-based DR programs). Generally, in order to trade power in the balancing market, a two-price scheme is used as follows:

Law1: if the power system imbalance is negative, i.e. the deficit of energy in the electricity market, the balancing price is as follows [48]:

$\forall \mathrm{t} \in\left\{\tau, \ldots, \mathrm{N}_{\tau}\right\}: \mid \begin{aligned} & \lambda_{\mathrm{t}}^{\mathrm{BM}(+)}=\lambda_{\mathrm{t}}^{\mathrm{DA}} \\ & \lambda_{\mathrm{t}}^{\mathrm{BM}(-)} \geq \lambda_{\mathrm{t}}^{\mathrm{DA}}\end{aligned}$

Law2: if the power system imbalance is positive, i.e. excess of energy in the electricity market, the balancing price is as follows:

$\forall \mathrm{t} \in\left\{\tau, \ldots, \mathrm{N}_{\tau}\right\}: \mid \begin{aligned} & \lambda_{\mathrm{t}}^{\mathrm{BM}(-)}=\lambda_{\mathrm{t}}^{\mathrm{DA}} \\ & \lambda_{\mathrm{t}}^{\mathrm{BM}(+)} \leq \lambda_{\mathrm{t}}^{\mathrm{DA}}\end{aligned}$ 
Note that \pm subscripts show balancing prices for positive/ negative imbalances. The two laws enforce that the deviations with opposite direction to the power system imbalance are priced at the day-ahead market price. The reason is that these deviations provide up-/down-regulation as the power system needs. In contrast, imbalances with the same direction of the system are settled at the clearing price of the balancing market.

\section{Conclusion}

In this paper, demand response programs for the agricultural sector is comprehensively described. First of all, two kinds of power systems were identified from the viewpoint of renewable power penetration. Afterward, the flexibility requirements of the two types of power systems are introduced.

In order to suggest demand response programs applicable in the agricultural sector, the technical and regulatory barriers were illustrated. To break the barriers, practical solutions were offered. In addition, great opportunities were provided to facilitate the integration of agricultural demand response programs to the power systems.

The results showed that there are some technical barriers in the agricultural demand response programs. In this way, Irrigation capacity, time of water delivery, irrigation source, irrigation method, crew availability, communication system, financial incentive and distribution system are the most important barriers. In order to lower the barriers, workable solutions were proposed as follows:

- Rescheduling the timetable of water delivery

- Installing a water reservoir in farms

- Allocating incentives-based DR programs to farmers

- Using Variable Speed Drive (VSD) pumps

- Installing on-farm power generation from renewable resources

- Using photovoltaic (PV) pumps

Finally, in order to guarantee power system flexibility, basic structures were suggested to the agricultural demand response aggregators (ADRA). The suggested ADRA integrates the farm flexibilities from $24 \mathrm{~h}$ prior to energy delivery time to near real time. The results showed that the ADRA is a clear need for future power system.

All in all, the main contributions of the paper can be stated as follows: (1) Classifying of the main barriers of agricultural demand response programs (2) Proposing workable solutions to break the barriers and (3) Suggesting a practical structure for agricultural demand response aggregator to facilitate the integration of farms flexibilities to the electricity market.

Although this paper conducted a comprehensive research study about the agricultural flexibility potentials, some critical issues remained for future researches. The following issues can be innovative ideas for future researches in this area:

1) Providing a coordination technique between ADRAs and other aggregators in the power system like industrial and residential demand response aggregators.

2) Investigating the flexibility potentials to the other types of farms, e.g. dairy industries or livestock.

3) Using data-driven approaches to estimate the power generation of on-farm solar/wind sites in the rural area without needing to install costly infrastructure.

\section{Compliance with Ethical Standards}

Conflict of Interests The authors declare that there is no conflict of interests.

\section{References}

1. H. Golmohamadi, R. Keypour, A. Hassanpour and M. Davoudi, "optimization of green energy portfolio in retail market using stochastic programming," in North American Power Symposium (NAPS), Charlotte, 2015

2. A. Najafi, M. Marzband and B. Mohamadi-Ivatloo, (2019) Uncertainty-Based Models for Optimal Management of Energy Hubs Considering Demand Response. Energies, 12(8):

3. "Market model 2.0, electricity market of the future" (2019) [Online]. Available: www.energinet.dk

4. Golmohamadi H, Keypour R (2018) Stochastic optimization for retailers with distributed wind generation considering demand response. J Modern Power Syst Clean Energy 6(4):733-748

5. S. Klaus, P. Amalia and B. K. Kenneth (2015) "Use of electric vehicles or hydrogen in the Danish transport sector," in International Conference on Energy, Environment and Climate Change

6. Golmohamadi H, Ramezani M, Bashian A, Falaghi H (2014) Riskbased maintenance scheduling of generating units in the deregulated environment considering transmission network congestion. J Modern Power Syst Clean Energy 2(2):150-162

7. "The World Bank," 2019. [Online]. Available: https://data. worldbank.org/indicator/EG.USE.ELEC.KH.PC

8. H. Golmohamadi and R. Keypour,(2017) "Retail Energy Management in Electricity Markets: Structure, Challenges and Economic Aspects- a Review." Techn Econ Smart Grids Sust Energ. 2(1):

9. Chang L, Chung Y. and Wang CS (2016) "Demand Response and Ancillary Service Management Using Fractional-Order Integral Indicator and Dynamic Game Model for an Aggregator Program in Smart Grids". Technol Econ Smart Grids Sustaine Energy

10. H. Golmohamadi, R. Keypour, B. Bak-Jensen and P. Radhakrishna (2019) "Optimization of household energy consumption towards day-ahead retail electricity price in home energy management systems". Sustainable Cities Soc. 47

11. Pourghaderi N, Fotuhi-Firuzabad M, Moeini-Aghtaie M, Kabirifar $\mathrm{M}$ (2018) Commercial demand response programs in bidding of a technical virtual power plant. IEEE Trans Ind Inform 14(11):5100 5111

12. Golmohamadi H, Keypour R, Bak-Jensen B, Radhakrishna Pillai J (2019) Robust self-scheduling of operational processes for 
industrial demand response aggregators. IEEE Trans Ind Electron. https://doi.org/10.1109/TIE.2019.2899562

13. Nejad MA, Golmohamadi H, Bashian A, Mahmoodi H, Hammami M (2017) "application of demand response programs to heavy industries: a case study on a regional electric company," in 32th International Power System Conference (PSC). Tehran, Iran

14. Marks G, Wilcox E (2013) Opportunities for demand response in California agricultural irrigation: a scoping study. The US Department of Energy (DOE), California

15. D. Olsen, A. Aghajanzadeh and A. McKane, "Opportunities for automated demand response in California agricultural irrigation," Lawrence Berkeley National Laboratory, 2015

16. Mendoza EMC, Perez RR, Moriano JJS (2016) Design of Neurofuzzy controller for control of water distribution in an irrigation Main Canal. IEEE Lat Am Trans 14(2):471-476

17. Endo A, Tsurita I, Burnett K, Orencio PM (2017) A review of the current state of research on the water, energy, and food nexus. Journal of Hydrology: Regional Studies 11:20-30

18. R. J.Chilundo, G. A.Maúre and U. S. Mahanjane (2019) "Dynamic mathematical model design of photovoltaic water pumping systems for horticultural crops irrigation: A guide to electrical energy potential assessment for increase access to electrical energy". J Cleaner Prod. 238:

19. Y. Bakelli and A. Kaabeche (2019) "Optimal size of photovoltaic pumping system using nature-inspired algorithms," Int Trans Electr Energy Syst. 29( 9):

20. Chrouta J, Chakchouk W, Zaafouri A, Jemli M (2019) Modeling and control of an Irrigation Station process using heterogeneous cuckoo search algorithm and fuzzy logic controller. IEEE Trans Ind Appl 55(1):976-990

21. Liu J, Chai Y, Xiang Y, Zhang X, Gou S, Liu Y (2018) Clean energy consumption of power systems towards smart agriculture: roadmap, bottlenecks and technologies. CSEE J Power Energy Syst 4(3):273-282

22. Aghajanzadeh A, Therkelsen P (2019) Agricultural demand response for decarbonizing the electricity grid. J Clean Prod 220: $827 \mathrm{e} 835$

23. C. Ning and F. You ( 2019) "Data-driven Wasserstein distributionally robust optimization for biomass with agricultural waste-to-energy network design under uncertainty," Appl Energy. 225

24. Golmohamadi H, Keypour R (2018) A bi-level robust optimization model to determine retail electricity price in presence of a significant number of invisible solar sites. Sustainable Energy, Grids Networks 13:93-111

25. Zhang J, Campana PE (2018) The water-food-energy nexus optimization approach to combat agricultural drought: a case study in the United States. Appl Energy 227:449-464

26. Yu Y, Liu J (2018) Practicality of using solar energy for cassava irrigation in the Guangxi autonomous region, China. Appl Energy 230:31-41

27. "Iran Grid Management System," 2019. [Online]. Available: https://www.igmc.ir/Power-grid-status-report

28. "The Nord Pool Electricity Market," 2019. [Online]. Available: https://www.nordpoolgroup.com

29. C. Hitaj and S. Shellye (2016) "Trends in U.S. Agriculture's Consumption and Production of Energy: Renewable Power, Shale Energy, and Cellulosic Biomass," United States Department of Agriculture, The US
30. S. Takiyar and V. Singh (2015) "Trend analysis and evolution of short term load forecasting techniques," in International Conference on Reliability, Infocom Technologies and Optimization, India

31. D. Liu, K. Sun, H. Huang and P. Tang (2018) Monthly Load Forecasting Based on Economic Data by Decomposition Integration Theory. Sustainability. 10(9):

32. Simpson W, Gotham D (2014) Standard approaches to load forecasting and review of Manitoba hydro load forecast for needs for and alternatives to (NFAT). University of Manitoba, Canada

33. Alkhathami M (2015) Introduction to electric load forecasting methods. J Adv Elec Comp Eng 2(1):1-12

34. Zhang J, Wei Y-M, Li D, Tan Z, Zhou J (2018) Short term electricity load forecasting using a hybrid model. Energy 158:774-781

35. Farajian L, Moghaddasi R, Hosseini S (2018) Agricultural energy demand modeling in Iran: approaching to a more sustainable situation. Energy Rep 4:260-265

36. Chen X, Thorp KR, Ouyang Z, Hou Y, Zhoud B, Li Y (2019) Energy consumption due to groundwater pumping for irrigation in the North China plain. Sci Total Environ 669:1033-1042

37. R. Beard and S. Sanford (2019) "Conservation And Efficiency, Farm Equipment Efficiency" US Dep. Agric.

38. M. H. J. P. Gunarathna, K. Sakai, T. Nakandakari, M. Kazuro, T. Onodera, H. Kaneshiro, H. Uehara and K. Wakasugi (2017) "Optimized Subsurface Irrigation System (OPSIS): Beyond Traditional Subsurface Irrigation." Water. 9(8):

39. Bashian A, Hojat M, Javidi MH, Golmohamadi H (2014) Securitybased tariff for wheeling contracts considering fair congestion cost allocation. J Control, Autom Electr Syst 25(3):368-380

40. A. Bashian, M. Assili, A. Anvari-Moghaddam and O. R. Marouzi, "Co-optimal PMU and communication system placement using hybrid wireless sensors," Sustainable Energy, Grids and Networks, vol. 19,2019

41. H. Golmohamadi and M. Ramezani (2013) "Generating unit maintenance scheduling in power market based on fairness and competition," in 21st Iranian Conference on Electrical Engineering (ICEE), Mashhad, Iran

42. Shabani A, Sepaskhah AR, Khorramian M (2018) Mathematicaleconomic analysis to determine optimal applied water in case of crop Price depends on its quality. Int J Plant Prod 12(3):191-202

43. Khorramian M, Hosseinpour M (2016) Autumn sugar beet irrigation water optimization basis of yield and cost functions in north of the Khuzestan. J Irrig Sci Eng 39(3):95-106

44. Chan G, Asgarpoor S (2006) Optimum maintenance policy with Markov processes. Electr Power Syst Res 76:452-456

45. Mudlapur A, Ramana VV, Damodaran RV, Balasubramanian V, Mishra S (2019) Effect of partial shading on PV fed induction motor water pumping systems. IEEE Trans Energy Conversion 34(1):530-539

46. "National Agricultural Statistics Service," 2019. [Online]. Available: https://www.nass.usda.gov/

47. "U.S. Energy Information Administration (EIA)," 2019. [Online]. Available: https://www.eia.gov/

48. J. Morales, A. Conejo, H. Madsen, P. Pinson and M. Zugno (2014) Integrating renewables in electricity markets, Springer Publications

Publisher's Note Springer Nature remains neutral with regard to jurisdictional claims in published maps and institutional affiliations. 